\title{
Optimization of Natural Dyeing Using Ultrasonic Method and Biomordant
}

\author{
N. A. Abdul Rahman, R. Tajuddin, and S. M. Tumin
}

\begin{abstract}
Problem statement: Traditionally the dyeing of natural dyes from plant materials was done by boiling using roaches method which requires longer time, higher temperature and metallic mordant to get good color fastness. Metallic mordants usually used in dyeing posed some serious bad effect to ecological. Thus this study explored a suitable technique for more efficient natural dyeing using suitable bio mordant to improve the color fastness of natural dyes on silk fabric. Approach: This study demonstrated ultrasonic cleaner as a technique of dyeing the colorant from a selected plant, i.e Xylocarpus moluccensis to a selected fabric, i.e silk. Colorant from combination of heartwood and bark (as a biomordant) of Xylocarpus moluccensis was dyed at different ultrasonic volume and time. Result: Results show the highest percentage of dye absorbed to silk fabric using ultrasonic cleaner was produced at optimum condition of medium sonic volume in 80 minutes time. Bark of Xylocarpus moluccensis was used as the biomordant to produce good color fastness properties to washing and perspiration. Conclusion: The utilization of ultrasonic cleaner and biomordant was found to have significant improvement in the dyeing color of natural dyes to silk fabric with lower dyeing temperature compared to traditional roaches method.
\end{abstract}

Index Terms - Ultrasonic cleaner, natural dye, anthraquinone, colorant, biomordant.

\section{INTRODUCTION}

Xylocarpus moluccensis belongs to family of Meliaceae, which can be found abundantly in littoral forest of the Malaysia Peninsula, Bengal, Burma, the Andaman's, Australia, Fiji and Africa [1]. It is used widely in timber production for construction of houses and boats. Aborigin people (Mah Meri community) of Pulau Carey, Malaysia are famous for its unique wooden statues and mask carved from Xylocarpus moluccensis heartwood. The waste from this handcraft production is therefore useful as a source of natural dyes for this study. Previously, Abd Razak et al., [2] reported Xylocarpus moluccensis heartwood as one of the potential natural dyes sources. They discovered that the colorant extracted correspond to anthraquinone compound.

Recently, there is a growing demand for developing suitable efficient dyeing technique for natural dyes from plant materials. Ultrasonic approach has been widely used mainly in food industry [3]-[5] and also in textile industry [6]-[8].

Manuscript received April 9, 2013; revised May 25, 2013.

N. A Abdul Rahman and R. Tajuddin are with the Department Chemistry, Faculty of Applied Sciences, Universiti Teknologi Mara, 40450 Shah Alam, Selangor, Malaysia (e-mail: norul22453@yahoo.com, ruziy039@salam.uitm.edu.my).

S. M. Tumin is with the Department Textile Technology, Faculty of Applied Sciences, Universiti Teknologi Mara, 40450 Shah Alam, Selangor Malaysia (e-mail: sitimarsinah@salam.uitm.edu.my).
Kamel et al., [8] used ultrasonic bench top cleaner bath for dyeing cotton fabric using colorant from Cochineal dye. They reported that the ultrasound approach improved dyeability as well as enhancement in the fastness properties of the dyed fabric. Mansour et al., [9] used elmasonic ultrasonic bath for dyeing pre-mordanted silk fabric from sticta coronata lichen. They reported that the use of ultrasonic energy showed a significant improvement in the dye uptake representing the sonication efficiency in textile dyeing with lower temperature $\left(60{ }^{\circ} \mathrm{C}\right)$. Normally, conventional dyeing temperature for silk fabric is 60 to $80{ }^{\circ} \mathrm{C}$. Dyeing temperature and time are important parameters which influenced silk dyeing. It is known that dyeing silk at high temperature for a long period of time tends to decrease the strength of silk fiber [10].

In this study ultrasonic cleaner approach was used in both extraction and dyeing process. Using ultrasonic in dyeing process can improve efficiency dye uptake to fabric and color fastness properties without longer dyeing time and higher temperature compared to traditional dyeing method.

\section{MATERIALS AND METHOD}

\section{A. Raw Materials}

The waste of heartwood and bark of Xylocarpus moluccensis was collected from the craft small industry located in the villages at Pulau Carey, Klang Selangor, Malaysia. The sample was then ground and stored at room temperature before use.

\section{B. Optimization of Ultrasonic Extraction Method}

Ultrasonic extraction was carried out as described in the previous part of this work [11].

\section{Optimization of Ultrasonic Dyeing Method}

Silk fabric was soaked in dye extract (approximately $1 \mathrm{~g}$ of heartwood and $7 \mathrm{~g}$ of bark of Xylocarpus moluccensis). The sample was placed into the ultrasonic cleaner for dyeing process. Parameters optimized were ultrasonic volume (low, medium, high) and extraction time $(20,40,60,80,100$ minutes).

$\%$ dyes absorb to textile $=($ weight use for dyeing - weight of remaining $) \times 100$ Weight of use for dyeing

\section{Conventional Dyeing Method}

Silk fabric was soaked in dye extract (approximately $1 \mathrm{~g}$ of heartwood and $7 \mathrm{~g}$ of bark of Xylocarpus moluccensis). The sample was placed into the roaches machine. The fabric was boiled at $60{ }^{\circ} \mathrm{C}$ in 80 minutes time. 


\section{E. Measurement of Color Fastness}

The dyed samples were tested according to ISO Malaysia standard methods for color fastness to washing and perspiration.

\section{F. Color Measurement}

Color of extract was measured using Lab Scan XE UV-visible spectrophotometer based on CIE system (International Commission on Illumination). The reference illumination was D65 (standard daylight), expressed as L*, a* and $b^{*}$ which representing lightness $\left(\mathrm{L}^{*}\right)$, redness $\left(+\mathrm{a}^{*}\right)$, greenness $\left(-a^{*}\right)$, yellowness $\left(+b^{*}\right)$, and blueness $\left(-b^{*}\right)$. From the $\mathrm{L}^{*}, \mathrm{a}^{*}$, and $\mathrm{b}^{*}$ coordinates, chroma $\left(\mathrm{C}^{*}\right)$ and hue angle $\left(\mathrm{h}^{\mathrm{o}}\right)$ values were calculated by using the following equation:

$$
C *=\sqrt{ }\left(a^{* 2}+b^{* 2}\right) \text { and } h^{o}=\tan ^{-1}(b * / a *)
$$

Chroma measures the intensity or saturation of the colorant while hue angle $\left(\mathrm{h}^{\circ}\right)$ is expressed on $360^{\circ}$ grid to show the tonality of the color. Hue angle $\left(\mathrm{h}^{\circ}\right)$ represent red at $0^{\circ}$ (or $360^{\circ}$ ), blue at $270^{\circ}\left(\right.$ or $-90^{\circ}$ ), yellow at $90^{\circ}$ and green color at $180^{\circ}$ (or $-80^{\circ}$ ).

\section{RESULT}

A preliminary study consisting of various experiments were carried out in order to determine the role of dyeing time and ultrasonic volume involved in the ultrasonic-assistance dyeing of Xylocarpus moluccensis. The percentages of dye absorbed to silk fabric against dyeing temperature and sonic volume is shown in a plot in Fig. 1.

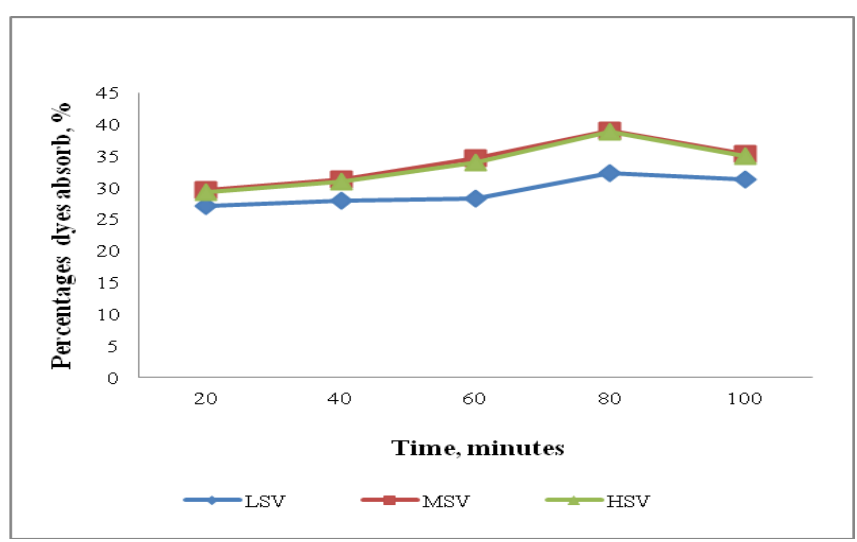

Fig. 1. Effect of dyeing time and sonic volume on percentages of dyes absorb

As shown in Fig. 1, the percentages of dyes absorbed to silk fabric increased with the increasing of dyeing time and reached maximum at 80 minutes. A further increase in time resulted in a declined plot.

Ultrasonic volume is also an important parameter for the ultrasonic-assistance dyeing as the effectiveness of the dyeing depends on it. Result in Fig.1 shows that the highest percentage yield of dyes absorbed after dyeing was produced at medium sonic volume and it was not significant by changed with higher sonic volume.

The measurement of chromaticity values such as $\mathrm{L}^{*}, \mathrm{a}^{*}, \mathrm{~b}^{*}$ as well as $\mathrm{h}^{\circ}$ and chroma $\mathrm{C}^{*}$ was then used to evaluate the dyed silk fabrics obtained by ultrasonic method. Table I shows the values of $\mathrm{L}^{*}, \mathrm{a}^{*}, \mathrm{~b}^{*}$ obtained from measurement using Lab Scan XE UV-spectrophotometer based on CIE system. Hue angle, $\mathrm{h}^{\mathrm{o}}$ and chroma, $\mathrm{C}^{*}$ values were calculated using the equation mentioned earlier.

TABLE I: COLOR MEASUREMENT OF DYED SILK FABRIC WITH XYLOCARPUS MOLUCCENSIS DYES

\begin{tabular}{|c|c|c|c|c|c|}
\hline $\begin{array}{l}\text { Sonic } \\
\text { volume }\end{array}$ & Lightness, $\mathrm{L}^{*}$ & $a^{*}$ & $\mathrm{~b}^{*}$ & $\mathrm{C}^{*}$ & $\mathrm{~h}^{\mathrm{o}}$ \\
\hline LSV 20 & 52.93 & 15.26 & 19.32 & 24.62 & 51.70 \\
\hline LSV 40 & 51.67 & 15.83 & 19.42 & 25.05 & 50.82 \\
\hline LSV 60 & 53.29 & 14.81 & 18.88 & 24.00 & 51.89 \\
\hline LSV 80 & 54.17 & 15.96 & 19.52 & 25.21 & 50.73 \\
\hline LSV 100 & 53.86 & 15.62 & 18.62 & 24.30 & 50.00 \\
\hline MSV 20 & 52.66 & 15.12 & 17.51 & 23.13 & 49.19 \\
\hline MSV 40 & 52.33 & 16.59 & 19.34 & 25.48 & 49.38 \\
\hline MSV 60 & 53.39 & 16.09 & 19.4 & 25.20 & 50.34 \\
\hline MSV 80 & 49.73 & 20.04 & 18.08 & 26.99 & 42.06 \\
\hline MSV 100 & 52.91 & 15.83 & 18.91 & 24.66 & 50.07 \\
\hline HSV 20 & 49.52 & 15.43 & 17.88 & 23.62 & 49.21 \\
\hline HSV 40 & 52.1 & 15.98 & 18.14 & 24.17 & 48.62 \\
\hline HSV 60 & 53.25 & 15.18 & 18.19 & 23.69 & 50.15 \\
\hline HSV 80 & 52.57 & 16.35 & 18.28 & 24.53 & 48.19 \\
\hline HSV 100 & 51.41 & 16.18 & 17.56 & 23.88 & 47.34 \\
\hline
\end{tabular}

$\mathrm{LSV}=$ lower sonic volume, $\mathrm{MSV}=$ medium sonic volume, $\mathrm{HSV}=$ high sonic volume, time $=20,40,60,80,100$.

The chromaticity values shown in Table I were comparable for all dyed fabrics except for that obtained at MSV 80. The value of $\mathrm{a}^{*}$ which represent the redness effect for dyed fabric was significantly higher at MSV 80 compared to those at other sonic volume. This indicates that, the $h^{0}$ value for the dyed fabric at MSV 80 was red-orange whereas the rest of other dyed silk fabrics were more towards yellowish orange.

The fastness properties of dyed silk fabrics toward washing and perspiration shown in Table II. Washing fastness for all dyed silk fabrics was good with range between 4 to $4 / 5$ for change in color and respectively good between 4 to 5 for staining. The same results were obtained for fastness properties to perspiration which rating from $4 / 5$ to 5 for both change in color and staining.

The percentage of dyes adsorb using ultrasonic cleaner dyeing method at optimum condition was then compared to that of boiling using the classical roaches method. The result in Fig. 2 show that the percentages of dye absorbed to silk fabric was higher by using ultrasonic method, 39.01\% compared to roaches method $32.3 \%$.

The color measurement of dyed silk fabric using ultrasonic and roaches method is tabulated in Table III. By using ultrasonic dyeing technique, dyed silk fabric showed more redness effect (42.06o) compared to that of roaches method. While, the color of dyed fabric by roaches method was more to yellowish orange as represented by hue angle of $47.62 \mathrm{o}$. 
TABLE II: FASTNESS PROPERTIES OF THE FABRIC DYED BY XYLOCARPUS MOLUCCENSIS.

\begin{tabular}{|c|c|c|c|c|c|c|c|}
\hline \multirow[t]{3}{*}{$\mathrm{UCV}$} & \multirow{3}{*}{$\begin{array}{l}\text { Time, } \\
\text { Min }\end{array}$} & \multicolumn{3}{|c|}{ Washing } & \multicolumn{3}{|c|}{ Perspiration } \\
\hline & & \multirow[t]{2}{*}{$\begin{array}{l}\text { Change } \\
\text { in color }\end{array}$} & \multicolumn{2}{|c|}{ Staining } & \multirow[t]{2}{*}{$\begin{array}{l}\text { Change } \\
\text { in color }\end{array}$} & \multicolumn{2}{|c|}{ Staining } \\
\hline & & & Cotton & Silk & & Cotton & Silk \\
\hline \multirow{5}{*}{ LSV } & 20 & 4 & 4 & $4 / 5$ & 5 & $4 / 5$ & $4 / 5$ \\
\hline & 40 & 4 & $4 / 5$ & $4 / 5$ & $4 / 5$ & $4 / 5$ & $4 / 5$ \\
\hline & 60 & 4 & $4 / 5$ & $4 / 5$ & $4 / 5$ & $4 / 5$ & $4 / 5$ \\
\hline & 80 & 4 & $4 / 5$ & $4 / 5$ & 5 & $4 / 5$ & $4 / 5$ \\
\hline & 100 & 4 & $4 / 5$ & $4 / 5$ & $4 / 5$ & 5 & $4 / 5$ \\
\hline \multirow{5}{*}{ MSV } & 20 & 4 & $4 / 5$ & $4 / 5$ & 5 & 5 & $4 / 5$ \\
\hline & 40 & 4 & 5 & $4 / 5$ & $4 / 5$ & 5 & 5 \\
\hline & 60 & 4 & 5 & 5 & $4 / 5$ & 5 & 5 \\
\hline & 80 & $4 / 5$ & 5 & 5 & 5 & 5 & $4 / 5$ \\
\hline & 100 & $4 / 5$ & $4 / 5$ & $4 / 5$ & $4 / 5$ & $4 / 5$ & $4 / 5$ \\
\hline \multirow{5}{*}{ HSV } & 20 & 4 & $4 / 5$ & $4 / 5$ & 5 & $4 / 5$ & $4 / 5$ \\
\hline & 40 & 4 & 5 & $4 / 5$ & $4 / 5$ & $4 / 5$ & $4 / 5$ \\
\hline & 60 & 4 & $4 / 5$ & $4 / 5$ & $4 / 5$ & $4 / 5$ & $4 / 5$ \\
\hline & 80 & $4 / 5$ & $4 / 5$ & $4 / 5$ & $4 / 5$ & $4 / 5$ & 4 \\
\hline & 100 & $4 / 5$ & $4 / 5$ & $4 / 5$ & $4 / 5$ & $4 / 5$ & $4 / 5$ \\
\hline
\end{tabular}

$\mathrm{LSV}=$ lower sonic volume, $\mathrm{MSV}=$ medium sonic volume, $\mathrm{HSV}=$ high sonic volume

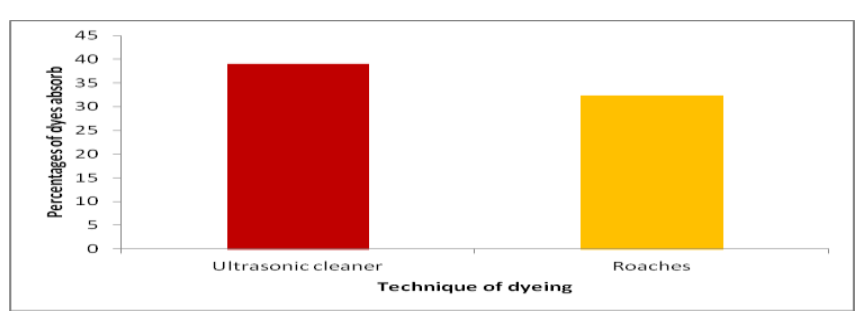

Fig. 2. Comparison of the percentages of dyes absorb to the silk fabric using ultrasonic and roaches method in 80 minutes.

TABLE III: COLOR MEASUREMENT OF DYED SILK FABRIC OBTAINED BY USING ULTRASONIC AND ROACHES METHOD

\begin{tabular}{llllll}
\hline Technique & $\mathrm{L}^{*}$ & $\mathrm{a}^{*}$ & $\mathrm{~b}^{*}$ & $\mathrm{C}^{*}$ & $\mathrm{~h}^{\mathrm{o}}$ \\
\hline Ultrasonic & 49.73 & 20.04 & 18.08 & 26.99 & 42.06 \\
Roaches & 49.84 & 18.80 & 20.60 & 27.89 & 47.62 \\
\hline
\end{tabular}

Table IV shows the comparison between fastness properties of dyed silk fabrics using ultrasonic and roaches method. Washing fastness and perspiration for dyed silk fabrics obtained using both methods was good for changes in color and staining. However by using ultrasonic-assistant dyeing, fastness properties to washing and perspiration were slightly improved.

In this study, the effect of using biomordant in dyeing process was also investigated. Mordant are substances which are used to fix dye to fabrics, and prevent the color from either fading with exposure to light or washing out. Normally, metallic mordants such as $\mathrm{Fe}, \mathrm{Al}, \mathrm{Cu}, \mathrm{Pb}, \mathrm{Sn}$ and others were used in dyeing. These metals might be found in plant although in small quantity which act as minerals/nutrien for the plant to grow. They have a chelating agent characteristic which assist the process of dyeing as reported by Vankar et al., [12]. However, metallic mordant can cause serious bad effect to ecological. Thus in this study, bark of Xylocarpus moluccensis was tested to be used as a biomordant.

TABEL IV: COLOR FASTNESS PROPERTIES OF THE FABRIC DYED BY USING ULTRASONIC AND ROACHES METHOD.

\begin{tabular}{lcccccc}
\hline \multirow{2}{*}{ Method } & \multicolumn{3}{c}{ Washing } & \multicolumn{3}{c}{ Perspiration } \\
\cline { 2 - 6 } & $\begin{array}{l}\text { Change } \\
\text { in }\end{array}$ & \multicolumn{2}{c}{ Staining } & Change in & \multicolumn{2}{c}{ Staining } \\
\cline { 2 - 6 } & color & Cotton & Silk & color & Cotton Silk \\
\hline Ultrasonic & $4 / 5$ & 5 & 5 & 5 & 5 & $4 / 5$ \\
Roaches & 4 & $4 / 5$ & $4 / 5$ & $4 / 5$ & 4 & 4 \\
\hline
\end{tabular}

Fig. 3 shows the tonality of dyed fabrics getting darker gradually with the increasing ratio of bark (as biomordant) to heartwood. This indicates an increase in the color strength with increasing quantity of biomordant and it reached maximum at $7 \mathrm{~g}$ of biomordant. A further increase in quantity of biomordant resulted in decrease of color strength. This was supported by Guesmi et al., [13] whereby they reported in their study that the color strength of dyed wool fibres increase with increasing of biomordant concentration.

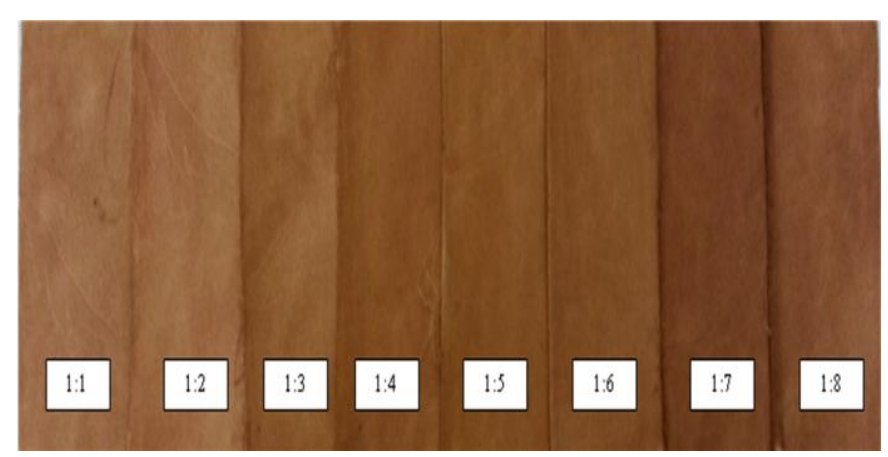

Fig. 3. The darkness of dyed fabric increased with the increasing ratio of bark to heartwood $(1 \mathrm{~g})$.

\section{CONCLUSION}

The use of ultrasonic dyeing method and biomordant (bark of Xylocarpus moluccensis) was found to have significant improvement in the percentages of dye absorbed to fabric and fastness properties of dyed silk fabric with lower temperature compared to roaches method. In this study, the operating condition for the ultrasonic dyeing of natural dye from Xylocarpus moluccensis was optimized at 80 minutes and medium sonic volume with lower dyeing temperature $\left(49^{\circ} \mathrm{C}\right)$.

\section{ACKNOWLEDGEMENT}

We wish to express our gratitude to the Faculty of Applied Sciences, Universiti Teknologi Mara Shah Alam for the support.

\section{REFERENCES}

[1] S. J. Uddin, J. A. Shilpi, S. M. S Alam, M. Alamgir, M. T. Rahman, and S. D. Sarker. "Antidiarrhoel activity of the methanol extract of the barks of Xylocarpus moluccensis in castor oil- and magnesium sulphate-induced diarrhea models in mice," Journal of Empharmacolog, vol. 101, pp. 139-143, 2005.

[2] N. Abd Razak, S. M. Tumin, and R. Tajuddin. "Effect of temperature on the color of natural dyed extract using pressurized hot water 
extraction method," American Journal of Applied Sciences., vol. 8, no. 1, pp. 45-49, 2011.

[3] S. R. Pai, M. S. Nimbalkar, N. V. Pawar, and G. B. Dixit, "Optimization of extraction technique and quantification of Betulinic acid (BA) by RP-HPLC method from Ancistrocladus heyneanus Wall. Ex Grah," Industrial Crops and Products, vol. 34, pp. 1458-1464, 2011,

[4] G. Zhang, L. He, and M. Hu, "Optimized ultrasonic-assisted extraction of flavonoids from Prunella vulgaris L. and evalution of antioxidant activities in vitro," Innovative Food Science and Emerging Technologies, vol. 12, pp. 18-25, 2011.

[5] M. H. Lee and C. C. Lin, "Comparison of techniques for extraction of isoflavones from the root of Radix Puerariae: Ultrasonic and pressurized solvent extractions," Food Chemistry, vol. 105, pp. 223-228, 2011

[6] V. Sivakumar, J. Vijaeeswarri, and J. Lakshmi Anna, "Effective natural dye extraction from different plant materials using ultrasound," Industrial Crops and Products., vol. 33, pp. 116-122, 2011.

[7] G. Cuoco, C. Mathe, P. Archier, F. Chemat, and C. Vieillescazes, "A multivariate study of performance of an ultrasound-assisted madder dyes extraction and characterization by liquid chromatography-photodiode array detection," Ultrasonic Sonochemistry., vol. 16, pp. 75-82, 2009.

[8] M. M. Kamel, M. M. El Zawahry, N. S. E. Ahmed, and F. Abdelghaffar, "Ultrasonic dyeing of cationized cotton fabric with natural dye. Part 2: cationization of cotton using Quat 188," Industrial Crops and Products, vol. 34, pp. 1410-1417, 2011.

[9] H. F. Mansour and S. Heffernan, "Environmental aspect on dyeing silk fabric with sticta coronta lichen using ultrasonic energy and mild mordants," Clean Techn Environ Policy., vol. 13, pp. 207-213, 2011.
[10] S. M. Burkinnshaw and N. Kumar. "The mordant dyeing of wool using tannic acid and FeSO4. Part 1. Initial findings," Dyes pigment, vol. 80, pp. 53-60, 2009.

[11] N. A. Abdul Rahman, S. M. Tumin, and R. Tajuddin, "Optimization of ultrasonic extraction method of natural dyes from Xylocarpus moluccensis," International Journal of Bioscience, Biochemistry and Bioinformatics., vol. 3, pp. 53-55, 2013.

[12] P. S. Vankar, R. Shanker, D. Mahanta, and S. C. Tiwari, "Ecofriendly sonicator dyeing of cotton with Rubia cordifolia Linn. using biomordant," Dyes and pigments., vol. 76, pp. 207-212, 2008.

[13] A. Guesmi, N. Ladhari, N. B. Hamadi, M. Msaddek, and F. Sakli, "First application of chlorophyll-a as biomordant: sonicator dyeing of wool with betanin dye," Journal of cleaner production, vol. 39, pp 97-104, 2013

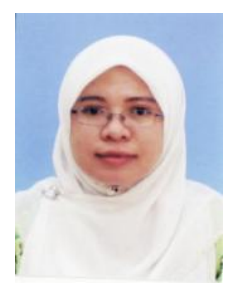

N. A. Abdul Rahman was born in Malacca, Malaysia on 15 January 1985. She has obtained Bachelor Science (hons) Applied Chemistry from Universiti Teknologi Mara Shah Alam, Malaysia in 2008. She has experience teaching secondary school for 3 years And now, she studies at Universiti Teknologi Mara Shah Alam, Malaysia as a master student.

R. Tajuddin is a lecture of Chemistry, Chemistry Department and Universiti Teknologi MARA Shah Alam, Malaysia. She has a experience on teaching for 20 years.

S. M. Tumin is a lecture of Textile, Textile Technology Department and Universiti Teknologi MARA Shah Alam, Malaysia. She has a experience on teaching for 20 years. 